\title{
Pulmonary Hypertension in Renal Disease: Epidemiology, Potential Mechanisms and Implications
}

\author{
B. Kawar ${ }^{a}$ T. Ellam ${ }^{a, c}$ C. Jackson ${ }^{b}$ D.G. Kiely ${ }^{d}$ \\ a Sheffield Kidney Institute and b Department of Cardiology, Northern General Hospital, ' Department of Cardiovascular \\ Science, University of Sheffield, and d Sheffield Pulmonary Vascular Disease Unit, Royal Hallamshire Hospital, Sheffield, UK
}

\section{Key Words}

Pulmonary hypertension - Chronic kidney disease .

End-stage renal disease - Uraemic vasculopathy

\begin{abstract}
Pulmonary hypertension $(\mathrm{PH})$ is highly prevalent in endstage renal disease. Several observational studies, based on an echocardiographic diagnosis of $\mathrm{PH}$, have suggested a prevalence of $30-60 \%$ and an association with increased mortality and poorer outcome following renal transplantation. The pathogenesis of $\mathrm{PH}$ in this population remains poorly understood. Reported associations include arteriovenous fistulae, cardiac dysfunction, fluid overload, bone mineral disorder and non-biocompatible dialysis membranes. However, due to the small numbers, the cross-sectional nature of the majority of studies in this field, and the reliance on echocardiography for the diagnosis of $\mathrm{PH}$, no consistent association with any individual risk factor has been demonstrated. There is no difference in prevalence between patients receiving different dialysis modalities and emerging evidence suggests that the onset of the condition may precede dialysis treatment in many patients. Furthermore, little is known about the impact of the 'uraemic vasculopathy' on the pulmonary vasculature. Given the
\end{abstract}

similarities between vascular changes in uraemia and those seen in pulmonary arterial hypertension, it is possible that a pulmonary vasculopathy may be present in a proportion of patients. There is a need for better understanding of the natural history and the pathogenesis of the condition which would help to individualise treatment of $\mathrm{PH}$ in end-stage renal disease. To enable such understanding, prospective adequately powered studies with an integrated investigational approach including right heart catheterisation are needed.

Copyright $\odot 2013$ S. Karger AG, Basel

\section{Introduction}

Pulmonary hypertension $(\mathrm{PH})$ is defined as mean pulmonary artery pressure (mPAP) of at least $25 \mathrm{~mm}$ $\mathrm{Hg}$ at rest. The consensus Dana Point classification categorises PH into 5 distinct groups based on the aetiology or pathophysiology (table 1) [1]. A distinction is made between pulmonary arterial hypertension (PAH) (group 1) and other causes of raised pulmonary arterial pressure such as heart failure. $\mathrm{PAH}$ is a progressive condition characterised by endothelial dysfunction and remodelling of pulmonary vascular medial and intimal

\section{KARGER}

E-Mail karger@karger.com

www.karger.com/ajn
(C) 2013 S. Karger AG, Basel

0250-8095/13/0373-0281\$38.00/0
Dr. Bisher Kawar

Sheffield Kidney Institute

Northern General Hospital

Herries Road, Sheffield S5 7AU (UK)

E-Mail bisher.kawar@sth.nhs.uk 
Table 1. Dana Point classification of $\mathrm{PH}$

\begin{tabular}{|c|c|c|}
\hline Group & Description & Examples \\
\hline 1 & Pulmonary arterial hypertension & $\begin{array}{l}\text { Idiopathic } \\
\text { Hereditary } \\
\text { Bone morphogenetic protein receptor } 2 \\
\text { Activin receptor-like kinase 1, endoglin } \\
\text { Unknown } \\
\text { Drug and toxin-induced } \\
\text { Associated with } \\
\text { Connective tissue diseases } \\
\text { HIV infection } \\
\text { Portal hypertension } \\
\text { Congenital heart diseases } \\
\text { Schistosomiasis } \\
\text { Chronic haemolytic anaemia }\end{array}$ \\
\hline 2 & $\mathrm{PH}$ owing to left heart disease & Systolic dysfunction, diastolic dysfunction, valvular disease \\
\hline 3 & $\mathrm{PH}$ owing to lung diseases and/or hypoxia & $\begin{array}{l}\text { Chronic obstructive pulmonary disease, interstitial lung } \\
\text { disease, sleep-disordered breathing }\end{array}$ \\
\hline 4 & Chronic thromboembolic pulmonary hypertension & \\
\hline 5 & $\mathrm{PH}$ with unclear multifactorial mechanisms & $\begin{array}{l}\text { Haematological disorders, e.g. myeloproliferative disorders; } \\
\text { systemic disorders, e.g. sarcoidosis; metabolic disorders, } \\
\text { e.g. glycogen storage disease; chronic renal failure on dialysis }\end{array}$ \\
\hline
\end{tabular}

layers resulting in constrictive and occlusive vascular lesions respectively. To fulfil the diagnostic criteria for $\mathrm{PAH}$, the pulmonary capillary wedge pressure (PCWP) should be $<15 \mathrm{~mm}$ Hg with pulmonary vascular resistance $>3 \mathrm{WU}$.

Recent observational studies have reported a high prevalence of $\mathrm{PH}$ in end-stage renal disease (ESRD), particularly among haemodialysis (HD) patients [2-4] and an association with adverse outcomes.

On the Dana Point classification, $\mathrm{PH}$ in chronic renal failure is listed under 'group 5: PH with unclear multifactorial mechanisms'. Several studies have examined associations with potential causative factors such as arteriovenous fistulae (AVF) and bone mineral parameters $[5,6]$. There has been no strong association with any individual risk factor, though the majority of these studies have shown some association with echocardiographic measures of cardiac dysfunction.

For this review we searched the literature for studies investigating $\mathrm{PH}$ in chronic kidney disease (CKD) and ESRD. We summarise the current state of knowledge and its limitations; in particular, we consider whether PH in $\mathrm{CKD}$ is a vasculopathic process akin to $\mathrm{PAH}$ or is merely a manifestation of cardiac dysfunction, highlighting areas requiring further research.

\section{Epidemiology}

Prevalence estimates of $\mathrm{PH}$ in patients with $\mathrm{CKD}$ are based primarily on echocardiographic parameters with little validation using the recommended gold standard right heart catheterisation (RHC). Due to the lack of prospective case-controlled studies, the timing of $\mathrm{PH}$ onset and its cumulative incidence at progressive stages of CKD are unknown.

Data on $\mathrm{PH}$ prevalence among CKD stage 5 patients prior to the initiation of renal replacement therapy (RRT) are scarce. One retrospective cohort study by Yigla et al. [7] reported a prevalence of $13.7 \%$ among 127 pre-dialysis patients, but did not provide data regarding excretory function at the time of echocardiography. Another study reported a much higher prevalence of $\mathrm{PH}$ in patients with advanced CKD not on RRT (39\%), rising to $56 \%$ in those established on dialysis [8]. A similar prevalence in conservatively managed ESRD patients (32\%) was reported by Abdelwhab and Elshinnawy [9].

In patients established on RRT, PH has been reported to be more prevalent affecting $30-58 \%$ of patients receiving $\mathrm{HD}[2,4,10,11]$ with the largest and most recent study reporting a prevalence of $38 \%$ [12]. In patients receiving peritoneal dialysis (PD) the reported prevalence 
Table 2. Summary of studies

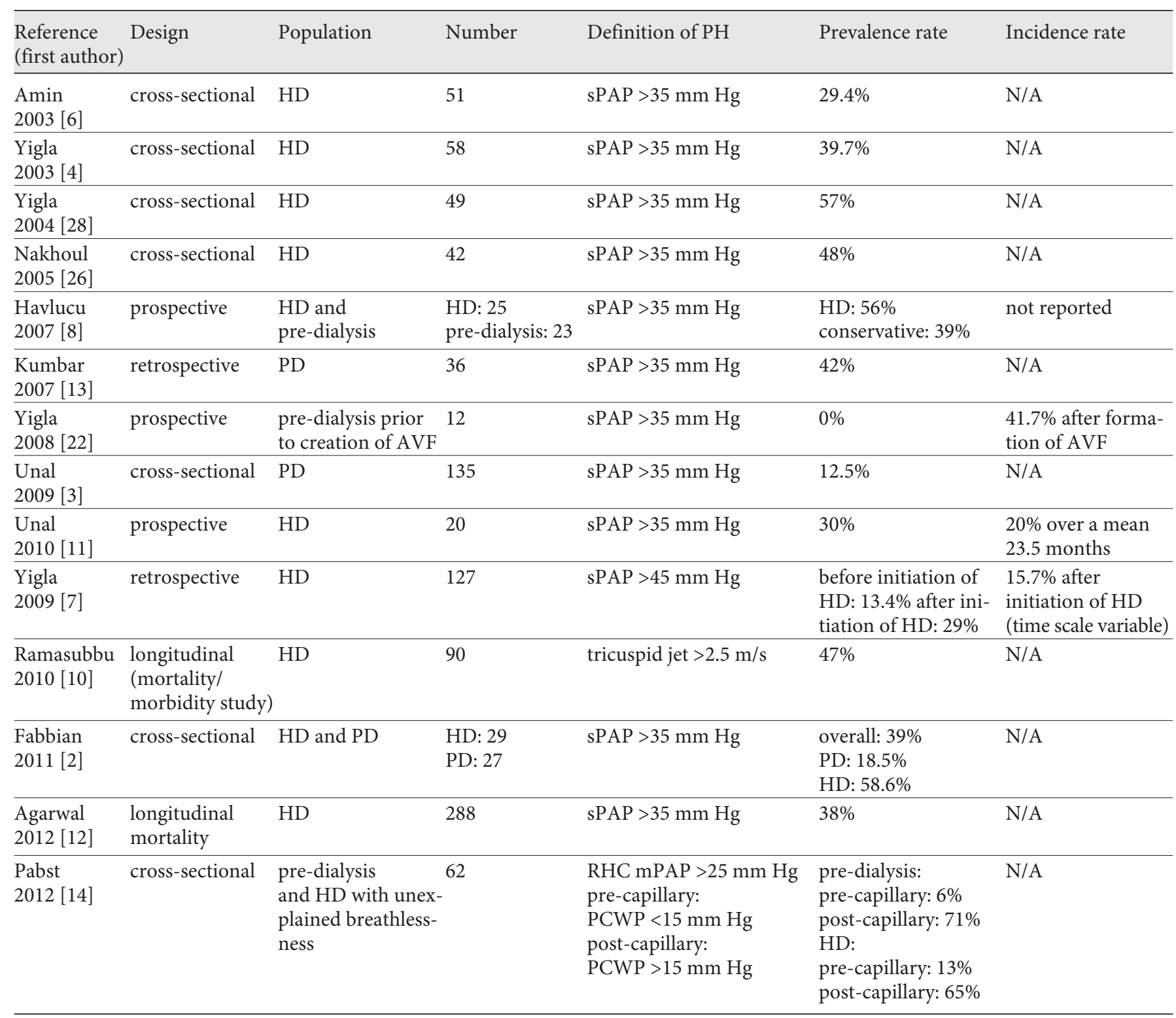

varies between 12.5 and $42 \%$ [13]. Table 2 summarises these studies.

The first right heart catheter-based study of $\mathrm{PH}$ prevalence in $\mathrm{CKD} / \mathrm{HD}$ was recently published by Pabst et al. [14] sub-classifying PH into pre- and post-capillary categories. This study compared the prevalence between a dialysis population and a pre-dialysis CKD4/5 population. In the dialysis group the prevalence was $72 \%$ which dropped to $60 \%$ when the measurements were repeated post-dialysis. In the pre-dialysis CKD group, the prevalence was $77 \%$, with no significant difference in preva- lence between the dialysis and the pre-dialysis populations. However, since unexplained dyspnoea was an inclusion criterion for this study, it does not provide a meaningful estimate of the true $\mathrm{PH}$ prevalence in dialysis and pre-dialysis populations.

No studies have reported a gender-specific risk for $\mathrm{PH}$ in renal disease. Similarly, studies that specifically looked at the prevalence of ischaemic a heart disease $[7,12,13$, 15] or traditional cardiac risk factors such as cholesterol or smoking $[2,3,6,13]$ reported no increased preponderance of these factors in patients with $\mathrm{PH}$. 


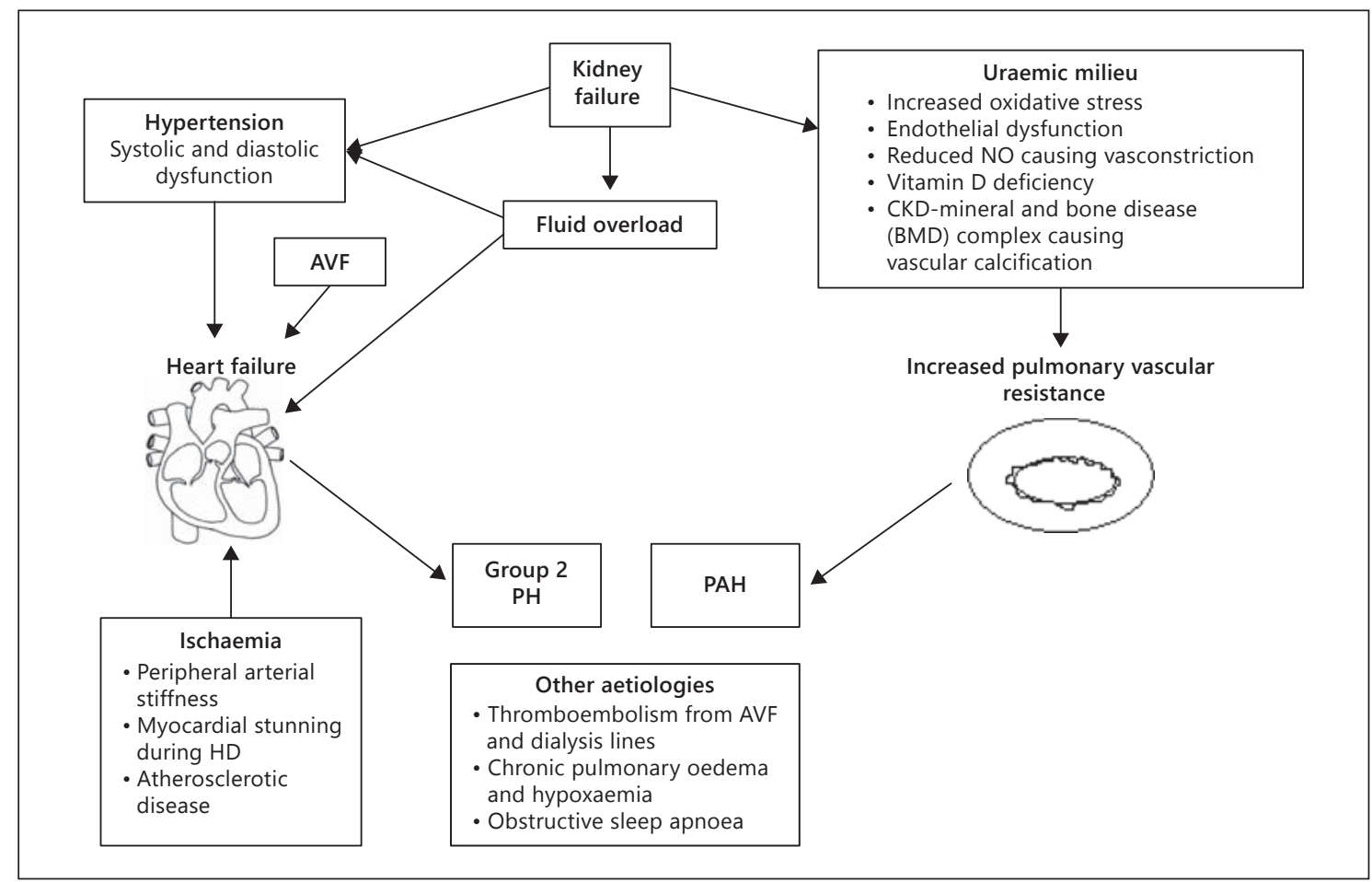

Fig. 1. Potential mechanisms contributing to $\mathrm{PH}$ in $\mathrm{CKD}$. Hypertension, fluid overload, AVF and myocardial ischaemia result in heart failure and group $2 \mathrm{PH}$, whilst uraemic vasculopathy (vascular calcification and endothelial dysfunction) may result in increased pulmonary vascular resistance and PAH-type pathology. Other contributing factors include thromboembolism from dialysis access, chronic pulmonary oedema and obstructive sleep apnoea.

\section{Prognostic Significance}

Two prospective studies have reported an association of $\mathrm{PH}$ with mortality among ESRD patients. In one study of 90 patients receiving $\mathrm{HD}$ treatment, the 1-year survival of patients with $\mathrm{PH}$ was $74 \%$, compared to $94 \%$ in patients without $\mathrm{PH}[10]$. However, these figures are not adjusted for co-morbidities known to impact on survival in dialysis patients. In a more recent study of 288 patients receiving $\mathrm{HD}$ treatment, $\mathrm{PH}$ was the strongest predictor of mortality with a hazard ratio of 2.17 in a multivariate model adjusting for age, race, HD access, serum albumin and history of cardiovascular disease. Age was the only other significant predictor of mortality in the model [12]. A retrospective study by Yigla et al. [7] also demonstrated an adverse outcome in $\mathrm{HD}$ patients with $\mathrm{PH}$ after adjusting for age and the presence of valvular heart disease. This was irrespective of whether the onset of $\mathrm{PH}$ was before or after the initiation of HD. In patients who receive a kidney transplant, there is some evidence that those with pre-existing $\mathrm{PH}$ have a lower survival [16] and higher risk of early allograft dysfunction [15].

\section{Pathophysiologic Mechanisms Explored So Far}

Several mechanisms for $\mathrm{PH}$ in advanced CKD have been proposed and are discussed below (fig. 1).

\section{Cardiac Dysfunction and Fluid Overload}

Both systolic and diastolic cardiac dysfunctions are common in CKD. There are numerous causes for heart failure in $\mathrm{CKD}$, including hypertension, salt and water overload, pleotropic effects of uraemic toxins and myocardial ischaemia. Most studies found correlations between the presence of $\mathrm{PH}$ and echocardiographic features of primary cardiac dysfunction. There is no consensus, however, regarding the echocardiographic findings that best predict $\mathrm{PH}$ in patients with advanced CKD or ESRD. In one study of 127 patients, of whom 37 had $\mathrm{PH}$ defined as an echocardiographically estimated systolic pulmonary artery pressure (sPAP) $>45 \mathrm{~mm} \mathrm{Hg}$, there was a significantly higher prevalence of valvular disease $(54 \%$ compared to $13 \%$ in those without $\mathrm{PH}$ ), mostly mild mitral regurgitation [7]. There was a significantly higher 
prevalence of left ventricular (LV) dilatation and systolic dysfunction, although there was no difference in the prevalence of LV diastolic dysfunction between patients with and without $\mathrm{PH}$.

A smaller study including 56 patients on HD and PD reported that $100 \%$ of those with $\mathrm{PH}$ had mitral valve incompetence [2], compared to $79 \%$ of those without $\mathrm{PH}$. Mitral valve incompetence in HD patients is usually functional and merely reflects the fluid status of the patient, with changes in severity according to timing of echocardiography in relation to dialysis and ultrafiltration [17]. The only other significant echocardiographic difference was ejection fraction which was significantly lower in the PH group (54 vs. 60\%). In the same study, a lower diastolic blood pressure was noted in patients with $\mathrm{PH}$ despite a similar systolic blood pressure. This may suggest a role for arterial stiffness in the pathogenesis of the condition, as low diastolic systemic blood pressure, especially in the context of wide pulse pressure in the elderly, has been associated with increased arterial stiffness and mortality [18].

In a study of patients receiving $\mathrm{PD}, \mathrm{LV}$ mass index, alongside low serum albumin and fluid overload, was a predictor of sPAP in a multivariate model [3]. Conversely, another study of patients receiving PD found no difference in the prevalence of LV hypertrophy, though LV dilatation was more prevalent in patients with $\mathrm{PH}$ [13].

Agarwal's study [12] also showed no difference in LV mass index between patients with $\mathrm{PH}$ and those without. In fact, paradoxically, patients with $\mathrm{PH}$ had a higher cardiac index and mid-wall fractional shortening implying a better systolic function. In a multivariate model, left atrial diameter was the strongest predictor of $\mathrm{PH}$. As left atrial diameter is a strong predictor of diastolic dysfunction, the findings suggest that in this group of patients, diastolic dysfunction may be a more relevant mechanism for $\mathrm{PH}$.

The diastolic dysfunction in advanced CKD patients is likely to be exacerbated by chronic fluid overload. To date, most studies of $\mathrm{PH}$ in CKD have failed to adequately adjust for fluid status. There are several reasons for this including the lack of a satisfactory definition of euvolaemia, the absence of a goldstandard method for assessing fluid status in the CKD population and the variation between patients in the ratio of total body water to intravascular volume.

The study of Unal et al. [3] tried to address the relationship between fluid overload and PH. Fluid overload was determined using bioimpedance studies and was expressed as extracellular to intracellular water ratio
(ECW:ICW). There was a significantly higher prevalence of $\mathrm{PH}$ in fluid overloaded compared to normovolaemic patients (27 vs. $3.6 \%)$ with a direct correlation between ECW:ICW ratio and PAP. However, whether optimising fluid status reduced PAP was not determined.

Pabst et al. [14] showed a significant reduction in PAP, and hence prevalence of $\mathrm{PH}$, when $\mathrm{RHC}$ and echocardiographic measurements were repeated post-dialysis. Such acute changes in PAP are most likely to be due to fluid ultrafiltration. The resultant drop in PCWP changed the diagnosis from post-capillary $\mathrm{PH}$ to pre-capillary $\mathrm{PH}$ (PAH) in 4 out of 24 patients. However, these findings should not be over-interpreted. Firstly, for the majority of the dialysis population, 'euvolaemia' achieved immediately post-dialysis is only short-lived as fluid starts to accumulate. Secondly, PCWP may be a poor indicator of LV end-diastolic pressure (LVEDP), where in one study about half of the patients diagnosed with $\mathrm{PAH}$ based on PCWP $<15 \mathrm{~mm} \mathrm{Hg}$ had elevated LVEDP on left heart catheterisation [19].

Of course, fluid overload may cause a direct lung injury from chronic pulmonary congestion adding yet a further pathophysiological mechanism to $\mathrm{PH}$ in these patients.

\section{Arteriovenous Fistulae}

AVF are considered the gold standard for HD access [20]. They result in increased venous return with a concomitant increase in cardiac output. Cases of 'high output cardiac failure' as a result of high AVF flow are not uncommon and often necessitate fistula ligation or reduction [21]. This was one of the first mechanisms proposed as a cause for $\mathrm{PH}$ in patients receiving $\mathrm{HD}$. Critics of this hypothesis argue that that increased venous return alone would be incapable of increasing pulmonary artery pressure due to the compliant nature of the normal pulmonary vascular circulation, suggesting that either the pulmonary vasculature is non-compliant in these patients or other pathophysiologic mechanisms are involved. In a small prospective study following up 12 patients after the formation of an AVF, Yigla et al. [22] showed that the only significant difference between patients who developed $\mathrm{PH}$ (5 patients out of 12) and those who did not was higher cardiac output, suggesting that in the setting of abnormal cardiac function, an increase in flow may result in an increase in mPAP.

Two studies found no correlation between AVF flow and $\mathrm{PH}$. Acarturk et al. [5] showed no significant difference in AVF flow between patients with $\mathrm{PH}$ and 
those without in a cross-sectional study. This was confirmed in a prospective study of 20 patients by Unal et al. [11] which demonstrated no correlation between PAP and AVF blood flow. In contrast to the study of Yigla et al. [22], they demonstrated no significant increase in the incidence of $\mathrm{PH}$ after the formation of AVF. Another study showed a considerable reduction in the prevalence of $\mathrm{PH}$ post-transplantation despite standard practice of leaving AVF in situ post-transplantation [23].

In summary, the current literature suggests that formation of AVF is not a primary determinant of the development of $\mathrm{PH}$ in $\mathrm{CKD}$.

\section{Uraemic Toxins, Inflammation and Endothelial Dysfunction}

A substantial body of evidence associates uraemia with chronic inflammation. Increases in pro-inflammatory monocytes, mast-cell proliferation, T-lymphocyte dysfunction, and decreased T-regulatory cells which result in an immune dysfunction are reported [24]. An increase in circulating inflammatory mediators also causes an increase in oxidative stress resulting in endothelial dysfunction. Patients with CKD have elevated levels of vasoconstrictors such as endothelin-1 and angiotensin II and reduced levels of endogenously produced vasodilators such as nitric oxide (NO) [25]. This imbalance of vasoactive peptides can directly affect pulmonary vascular tone and might mediate an increase in pulmonary vascular resistance causing PAH.

One study showed reduced NO levels and attenuated release of $\mathrm{NO}$ in response to $\mathrm{HD}$ in patients with $\mathrm{PH}$ compared to patients receiving HD without $\mathrm{PH}$ [26]. However, another study of 135 patients treated with PD showed no correlation between $\mathrm{PH}$ and asymmetric dimethylarginine, a uraemic toxin and inhibitor of NO synthase [3].

The direct effects of uraemic toxins are difficult to assess. Similarly, the effect of uraemic toxin clearance by dialysis on mortality is not fully understood. For example, the landmark HEMO study showed no overall survival benefit in patients receiving higher dose dialysis [27]. In Agarwal's study [12], a higher urea reduction ratio had a statistically significant protective effect from $\mathrm{PH}$ in a multivariate model. This may suggest a primary role for uraemic toxins in the pathogenesis of $\mathrm{PH}$.

\section{Bone Mineral Disorder}

A major component of vascular dysfunction in kidney disease is due to vascular calcification. Therefore, calcification of the pulmonary vasculature has been proposed as a mechanism contributing to $\mathrm{PH}$ in $\mathrm{CKD}$. One study correlated calcification score on scintigraphy scans with $\mathrm{PH}$ [28] and showed no association between the two. A number of studies have compared calcium, phosphate and parathyroid hormone (PTH) levels in patients with and without $\mathrm{PH}$, but the majority have failed to demonstrate an association $[2,6,22]$. Only one study showed a positive correlation between echocardiographically estimated sPAP and calcium, phosphate and PTH in PD patients [13]. Failure to show a consistent relationship between bone parameters and PAP may be due to the complexity of the relationship between those parameters and cardiovascular morbidity and mortality. For example, the association between phosphate and mortality is a J- or Ushaped relationship, presumably reflecting a high degree of inflammation and malnutrition in the low phosphate group and vascular dysfunction and calcification in the high phosphate group $[29,30]$. Another factor adding to the difficulty in clarifying the relationship between bone parameters and $\mathrm{PH}$ is the fact that imaging techniques such as scintigraphy only detect large/medium vessel calcification, when small vessel pathology is more likely to be relevant if $\mathrm{PH}$ is caused by an arteriopathy.

The study by Agarwal [12] demonstrated that the use of vitamin $\mathrm{D}$ analogues has an adjusted odds ratio of 0.41 for the presence of $\mathrm{PH}$. This is consistent with a body of evidence suggesting a protective effect of vitamin D against cardiovascular mortality in CKD [31]. However, interventional studies have yet to demonstrate a convincing cardiovascular benefit of active vitamin $\mathrm{D}$ administration in patients with kidney disease [32]. The recent EVOLVE study also failed to show a benefit of Cinacalcet treatment for hyperparathyroidism on a composite outcome of mortality and cardiovascular events in the primary analysis [33].

\section{Haemodialysis}

The increased preponderance of $\mathrm{PH}$ in the HD population raises the question of whether this is related to the dialysis process itself. In particular, it has been postulated that a significant inflammatory response to non-biocompatible membranes contributes to endothelial dysfunction and subsequently $\mathrm{PH}$. One study compared the changes in sPAP before and after a HD session with a cellulose membrane versus a biocompatible polysulphone high-flux dialyser. The study showed a greater reduction with the biocompatible high-flux dialyser that was not related to higher volume ultrafiltration [34]. These findings warrant further studies of the long-term impact of dialysis membranes on $\mathrm{PH}$. 


\section{Unexplored Potential Mechanisms}

There is a need to understand the phenomenon of $\mathrm{PH}$ in CKD in well-designed prospective studies taking these factors into consideration, and simultaneously evaluating cardiac dysfunction and markers of uraemic vasculopathy. The latter may prove to be an important mechanism akin to the process seen in PAH.

$\mathrm{PAH}$ is a progressive condition characterised by ongoing endothelial dysfunction and pulmonary vascular remodelling. The condition can be idiopathic, familial associated with specific mutations, or caused by systemic conditions such as connective tissue disease or HIV [1]. The vascular changes seen involve both the intimal and the medial layers. There is smooth muscle proliferation and matrix deposition resulting in constrictive vascular lesions. In addition, intimal hyperplasia leads to occlusive changes in the pulmonary arteries and the development of plexiform lesions. Several growth factors synthesised by dysfunctional endothelial cells have been implicated in this process including platelet-derived growth factor, epidermal growth factor and vascular endothelial growth factor. Endothelial dysfunction also results in increased synthesis of vasoconstrictors such as endothelin-1 and impaired synthesis of vasodilators such as NO. [35]. An up-regulation of some bone formation markers such as bone morphogenetic protein and osteoprotegrin have been reported in patients with $\mathrm{PH}$ [36].

There are similarities between this process and uraemic vasculopathy. The latter is also characterised by changes in the arterial intima and media that result in increased vascular stiffness and resistance [37]. These effects are well recognised in the systemic circulation and contribute to LV hypertrophy, but could also be important in the pulmonary circulation. Since uraemic vasculopathy is not a strictly pressure-dependent process, the lower pressures of the pulmonary compared to the systemic circulation would not necessarily confer protection from uraemic pathological remodelling. Conversely, the pulmonary vascular bed has distinct characteristics such as the response to hypoxia, that are different from the systemic circulation, thus extrapolation of data between the two systems is difficult. Active vitamin D suppresses proliferation of vascular smooth muscle cells [38], so a deficiency of active vitamin $\mathrm{D}$ in the setting of kidney disease (reflecting suppression of renal hydroxylation and prevalent 25-hydroxyvitamin $\mathrm{D}$ deficiency) may favour a hyperproliferative state similar to that seen in $\mathrm{PAH}$. Although vascular smooth muscle cell proliferation is not considered a major feature of systemic uraemic vascu-

Pulmonary Hypertension in Renal Disease lopathy, the uraemic-hyperphosphataemic osteochondroblastic transformation of vascular smooth muscle cells leads to arterial medial calcification and increased arterial stiffness [39]. Other mediators up-regulated by the osteochondroblastic vascular smooth muscle cell transformation, e.g. osteoprotegrin [40], could contribute to changes in the pulmonary vasculature similar to those of PAH. Impaired endothelial NO synthesis [41] and elevated levels of endothelin [25] are both features of kidney disease that cause systemic vasoconstriction but are also likely to affect the pulmonary vasculature. Therefore, although a true proliferative $\mathrm{PAH}$ pathology may not be induced by kidney disease, arterial changes accompanying uraemia could be a factor adding to the pulmonary resistance and right ventricular workload.

A recent association between low serum leptin levels (adjusted for BMI) and mortality in PAH has been reported [42]. A similar association between low leptin level and increased mortality among HD patients was previously reported [43]. This further suggests a similar underlying endothelial dysfunction given the stipulated role of leptin in the regulation of cardiovascular processes such as $\mathrm{NO}$ production.

In addition to cardiac and vascular mechanisms, there may also be a role for direct lung involvement in the development of $\mathrm{PH}$ in the dialysis population. Thrombi form both AVF and dialysis catheters and can lead to pulmonary thrombotic events. Septic or fibrin emboli may also result from long-term dialysis catheters. In addition, there is some evidence that the process of dialysis induces a degree of myocardial ischaemia with transient regional wall motion abnormalities [44]. This may have deleterious effects on other vascular beds, including the pulmonary bed, causing lung tissue ischaemia, another known cause for $\mathrm{PH}$. Sleep apnoea is also highly prevalent in the dialysis population and may contribute to the increased prevalence of $\mathrm{PH}$ [45].

\section{Limitations of Current Knowledge}

The classification of patients with $\mathrm{CKD}$ as having $\mathrm{PH}$ due to unclear/multifactorial causes is a reflection of our very limited understanding of the multifactorial pathophysiologic mechanisms underlying $\mathrm{PH}$ in these patients. The limitations of the current body of evidence relate to the reliance on echocardiography in diagnosing $\mathrm{PH}$, the lack of well-designed, adequately powered prospective studies, and the lack of mechanistic and pre-clinical studies. Some of these issues are discussed below. 


\section{Limitations of Echocardiography in the Diagnosis} of $\mathrm{PH}$

Various echocardiographic modalities have been utilised in the estimation of sPAP including tissue doppler echocardiography (DE), measurement of the tricuspid annular plane systolic excursion, two-dimensional strain, speckle tracking, acceleration time across the pulmonary valve, the pulmonary artery regurgitant jet method and the tricuspid regurgitant jet method [46].

The tricuspid regurgitant jet has been the most commonly used method in the studies mentioned in this review. A systematic review and meta-analysis of 29 studies with a total population of 1,998 subjects looked at the correlation of pulmonary pressures obtained by echocardiography versus RHC in order to determine the diagnostic accuracy of echocardiography for $\mathrm{PH}$ [46]. The correlation coefficient between sPAP estimated from echocardiography versus measured by RHC was 0.70 . The sensitivity and specificity for echocardiography in diagnosing $\mathrm{PH}$ were 83 and $72 \%$ respectively. The minimum sPAP for diagnosis of $\mathrm{PH}$ in these studies was $\geq 30$ $\mathrm{mm} \mathrm{Hg}$ for echo-derived measurements and sPAP $\geq 30$ $\mathrm{mm} \mathrm{Hg}$ or $\mathrm{mPAP} \geq 20 \mathrm{~mm} \mathrm{Hg}$ for RHC-derived measurements.

Another study assessed the diagnostic performance of $\mathrm{DE}$ done within $1 \mathrm{~h}$ of a right heart catheter and found that DE was inaccurate $(> \pm 10 \mathrm{~mm} \mathrm{Hg}$ difference in $48 \%$ of cases). The presence of a good correlation between $\mathrm{DE}$ and RHC does not necessarily mean that the former can be used as a substitute for the latter, and at best may serve as a screening or surveillance but not diagnostic tool [47].

In addition, echocardiography does not provide a measure of PCWP, hence estimation of pulmonary vascular resistance, the hallmark of $\mathrm{PAH}$, is not possible. Furthermore, right ventricular systolic pressure (considered equivalent to SPAP) is influenced by pre-load, including volume status and LV output, and hence does not accurately reflect changes in pulmonary vascular resistance. For example, a low right ventricular systolic pressure may be a result of reduced right ventricular output [48]. Furthermore, the timing of the measurement is also important in patients receiving HD. A pre-dialysis measurement is likely to overestimate PAP due to the fluid overload, whilst an immediate post-dialysis measurement may underestimate PAP due to redistribution of fluid for several hours post-dialysis. In addition to the fluid status, the transient myocardial stunning observed during dialysis [44] would clearly affect the echocardiographic findings, if done immediately post-HD.

\section{Study Design Issues}

Some of the limitations of the current literature are inherent to the individual study design. The majority of published studies are cross-sectional and observational. Some were designed to delineate the effect of a specific parameter such as AVF on the incidence or prevalence of $\mathrm{PH}$, whilst others compared clinical characteristics of patients with and without $\mathrm{PH}$. The small number of subjects in these studies, the retrospective nature of data collection in many of them and the non-invasive measures used to assess for the presence of $\mathrm{PH}$ are major limitations allowing only limited extrapolation.

Patients with cardiac abnormalities may have been overrepresented in many studies, such as those by Kumbar et al. [13] and Yigla et al. [7] that were retrospective and relied on historic echocardiograms. As historic echocardiograms may have been performed for the investigation of suspected cardiac dysfunction, data based on these patients would inevitably over-represent cardiac abnormalities and may exaggerate the true prevalence of $\mathrm{PH}$.

Therefore, to investigate the prevalence, determinants and consequences of $\mathrm{PH}$ in $\mathrm{CKD}$, prospective studies using RHC, preferably coupled with left heart catheterisation, need to be conducted. These studies should be accompanied by soluble and functional markers of vascular health such as cytokines, NO metabolites, assays of oxidative stress, pulse wave velocity and flow-mediated dilatation. An ideal study would be longitudinal, enrolling patients with advanced CKD and assessing the effects of interventions such as dialysis and transplantation. To date, there are no studies of the pulmonary vasculature in uraemic animal models.

\section{Impact on Clinical Practice and Therapeutic Potential}

It is unclear whether $\mathrm{PH}$ plays a causal role in the adverse outcomes in HD patients or is simply acting as a marker of more severe cardiac dysfunction. A PH-associated reduced capacity of the right heart to maintain adequate left heart filling pressures in the face of intermittent dialytic fluid removal could contribute to the intradialytic myocardial stunning, ischaemia and myocardial fibrosis recently described [49]. Since pro-arrhythmogenic myocardial remodelling is considered a major contributor to sudden cardiac death in the HD population, such a pathway is potentially of therapeutic importance.

Data from observational studies could help identify predictors or determinants of $\mathrm{PH}$ and offer new potential 
therapeutic targets for clinical trials. One such example is the identification of the use of vitamin $\mathrm{D}$ analogues by Agarwal [12] as a protective factor.

Thus far, no interventional studies have been performed in this group of patients. An understanding of the pathophysiology could help to identify therapeutic strategies. Identifying patients with a predominant vasculopathy could facilitate selection for treatment with vasodilator therapies such as phosphodiesterase inhibitors, endothelin receptor antagonists or prostanoid analogues that have been shown to improve exercise tolerance and reduce pulmonary vascular resistance in non-uraemic $\mathrm{PAH}$ patients [50-52]. On the other hand, those with predominant cardiac components could benefit from strategies aimed at improving cardiac function such as the use of renin-angiotensin-aldosterone system inhibitors, intense management of fluid status, or therapeutic reduction of AVF flow. It is of utmost importance that the latter group with LV pathology are differentiated from the PAH phenotype as the use PAH treatments in patients with $\mathrm{LV}$ failure can result in pulmonary oedema or even death.

When designing interventional trials, it is worth bearing in mind that patients with advanced CKD may have dual pathology due to the high prevalence of systolic and diastolic cardiac dysfunction in this population. The presence of the latter should not automatically exclude the co-existence of a PAH-type process, and therefore, patients should be properly assessed for evidence of PAH and enrolled in clinical trials appropriately.
Identifying patients with potential reversibility of their $\mathrm{PH}$ could improve the selection process for kidney transplantation. Epidemiological data suggest that there is a high mortality rate among these patients which would preclude many of them from being considered for transplantation. Since there is some evidence that $\mathrm{PH}$ improves post-transplantation, patients with potential for reversibility might merit treatment with vasodilators prior to consideration for kidney transplantation.

\section{Conclusion}

The mechanisms underlying development of $\mathrm{PH}$ in the uraemic population may be more complex than a mere manifestation of heart failure. To understand this further, prospective studies utilising RHC should be conducted to characterise patients with intrinsic increases in pulmonary vascular resistance compared to those with left heart failure and fluid overload. Identifying the predominant mechanism in a subgroup or an individual may help to develop and individualise treatments in the future. Until better understanding of the pathophysiology and effect of interventions such as the use of vasodilator treatments in this population becomes available, there is a call for a consensus involving nephrologists and $\mathrm{PH}$ specialists on how best to screen for, investigate and manage these patients, and a move away from simply labelling the condition as 'heart failure'.

\section{References}

1 Simonneau G, Robbins IM, Beghetti M, Channick RN, Delcroix M, Denton CP, Elliott CG, Gaine SP, Gladwin MT, Jing ZC, Krowka MJ, Langleben D, Nakanishi N, Souza R: Updated clinical classification of pulmonary hypertension. J Am Coll Cardiol 2009;54:S43-S54.

-2 Fabbian F, Cantelli S, Molino C, Pala M, Longhini C, Portaluppi F: Pulmonary hypertension in dialysis patients: a cross-sectional Italian study. Int J Nephrol 2010;2011:283475.

$\checkmark 3$ Unal A, Sipahioglu M, Oguz F, Kaya M, Kucuk H, Tokgoz B, Buyukoglan H, Oymak $\mathrm{O}$, Utas C: Pulmonary hypertension in peritoneal dialysis patients: prevalence and risk factors. Perit Dial Int 2009;29:191-198.

4 Yigla M, Nakhoul F, Sabag A, Tov N, Gorevich B, Abassi Z, Reisner SA: Pulmonary hypertension in patients with end-stage renal disease. Chest 2003;123:1577-1582.

5 Acarturk G, Albayrak R, Melek M, Yuksel S, Uslan I, Atli H, Colbay M, Unlu M, Fidan F, Asci Z, Cander S, Karaman O, Acar M: The relationship between arteriovenous fistula blood flow rate and pulmonary artery pressure in hemodialysis patients. Int Urol Nephrol 2008;40:509-513.

6 Amin M, Fawzy A, Hamid MA, Elhendy A: Pulmonary hypertension in patients with chronic renal failure: role of parathyroid hormone and pulmonary artery calcifications. Chest 2003;124:2093-2097.

$>7$ Yigla M, Fruchter O, Aharonson D, Yanay N, Reisner SA, Lewin M, Nakhoul F: Pulmonary hypertension is an independent predictor of mortality in hemodialysis patients. Kidney Int 2009;75:969-975.

$\checkmark 8$ Havlucu Y, Kursat S, Ekmekci C, Celik P, Serter S, Bayturan O, Dinc G: Pulmonary hypertension in patients with chronic renal failure. Respiration 2007;74:503-510.

$>9$ Abdelwhab S, Elshinnawy S: Pulmonary hypertension in chronic renal failure patients. Am J Nephrol 2008;28:990-997.

10 Ramasubbu K, Deswal A, Herdejurgen C, Aguilar D, Frost AE: A prospective echocardiographic evaluation of pulmonary hyper- tension in chronic hemodialysis patients in the United States: prevalence and clinical significance. Int J Gen Med 2010;3:279-286.

11 Unal A, Tasdemir K, Oymak S, Duran M, Kocyigit I, Oguz F, Tokgoz B, Sipahioglu MH, Utas C, Oymak O: The long-term effects of arteriovenous fistula creation on the development of pulmonary hypertension in hemodialysis patients. Hemodial Int 2010;14:398-402.

12 Agarwal R: Prevalence, determinants and prognosis of pulmonary hypertension among hemodialysis patients. Nephrol Dial Transplant 2012;27:3908-3914.

13 Kumbar L, Fein PA, Rafiq MA, Borawski C, Chattopadhyay J, Avram MM: Pulmonary hypertension in peritoneal dialysis patients. Adv Perit Dial 2007;23:127-131.

14 Pabst S, Hammerstingl C, Hundt F, Gerhardt T, Grohe C, Nickenig G, Woitas R, Skowasch D: Pulmonary hypertension in patients with chronic kidney disease on dialysis and without dialysis: results of the PEPPER-study. PLoS One 2012; 7:e35310. 
15 Zlotnick DM, Axelrod DA, Chobanian MC, Friedman S, Brown J, Catherwood E, Costa SP: Non-invasive detection of pulmonary hypertension prior to renal transplantation is a predictor of increased risk for early graft dysfunction. Nephrol Dial Transplant 2010;25: 3090-3096.

- 16 Issa N, Krowka MJ, Griffin MD, Hickson LJ, Stegall MD, Cosio FG: Pulmonary hypertension is associated with reduced patient survival after kidney transplantation. Transplantation 2008;86:1384-1388.

17 Cirit M, Ozkahya M, Cinar CS, Ok E, Aydin S, Akcicek F, Dorhout Mees EJ: Disappearance of mitral and tricuspid regurgitation in haemodialysis patients after ultrafiltration. Nephrol Dial Transplant 1998;13:389-392.

18 Van Bortel LM, Struijker-Boudier HA, Safar ME: Pulse pressure, arterial stiffness, and drug treatment of hypertension. Hypertension 2001;38:914-921.

- 19 Halpern SD, Taichman DB: Misclassification of pulmonary hypertension due to reliance on pulmonary capillary wedge pressure rather than left ventricular end-diastolic pressure. Chest 2009; 136:37-43.

-20 K/DOQI clinical practice guidelines for chronic kidney disease: evaluation, classification, and stratification. Am J Kidney Dis 2002; 39:S1-S266.

21 Basile C, Lomonte C, Vernaglione L, Casucci F, Antonelli M, Losurdo N: The relationship between the flow of arteriovenous fistula and cardiac output in haemodialysis patients. Nephrol Dial Transplant 2008;23:282-287.

-22 Yigla M, Banderski R, Azzam ZS, Reisner SA, Nakhoul F: Arterio-venous access in end-stage renal disease patients and pulmonary hypertension. Ther Adv Respir Dis 2008;2:49-53.

-23 Casas-Aparicio G, Castillo-Martinez L, OreaTejeda A, Abasta-Jimenez M, Keirns-Davies C, Rebollar-Gonzalez V: The effect of successful kidney transplantation on ventricular dysfunction and pulmonary hypertension. Transplant Proc 2010;42:3524-3528.

24 Swaminathan S, Shah SV: Novel inflammatory mechanisms of accelerated atherosclerosis in kidney disease. Kidney Int 2011;80:453463.

25 Dhaun N, Goddard J, Webb DJ: The endothelin system and its antagonism in chronic kidney disease. J Am Soc Nephrol 2006;17:943955.

-26 Nakhoul F, Yigla M, Gilman R, Reisner SA, Abassi Z: The pathogenesis of pulmonary hypertension in haemodialysis patients via arteriovenous access. Nephrol Dial Transplant 2005;20:1686-1692.

-27 Eknoyan G, Beck GJ, Cheung AK, Daugirdas JT, Greene T, Kusek JW, Allon M, Bailey J, Delmez JA, Depner TA, Dwyer JT, Levey AS, Levin NW, Milford E, Ornt DB, Rocco MV, Schulman G, Schwab SJ, Teehan BP, Toto R: Effect of dialysis dose and membrane flux in maintenance hemodialysis. N Engl J Med 2002;347:2010-2019.

-28 Yigla M, Keidar Z, Safadi I, Tov N, Reisner SA, Nakhoul F: Pulmonary calcification in hemodialysis patients: correlation with pulmonary artery pressure values. Kidney Int 2004;66: 806-810.

29 Block GA, Hulbert-Shearon TE, Levin NW, Port FK: Association of serum phosphorus and calcium $\times$ phosphate product with mortality risk in chronic hemodialysis patients: a national study. Am J Kidney Dis 1998;31:607-617.

30 Floege J, Kim J, Ireland E, Chazot C, Drueke T, de Francisco A, Kronenberg F, Marcelli D, Passlick-Deetjen J, Schernthaner G, Fouqueray B, Wheeler DC: Serum iPTH, calcium and phosphate, and the risk of mortality in a European haemodialysis population. Nephrol Dial Transplant 2011;26:1948-1955.

-31 Pilz S, Iodice S, Zittermann A, Grant WB, Gandini S: Vitamin D status and mortality risk in CKD: a meta-analysis of prospective studies. Am J Kidney Dis 2011;58:374-382.

32 Thadhani R, Appelbaum E, Pritchett Y, Chang Y, Wenger J, Tamez H, Bhan I, Agarwal R, Zoccali C, Wanner C, Lloyd-Jones D, Cannata J, Thompson BT, Andress D, Zhang W, Packham D, Singh B, Zehnder D, Shah A, Pachika A, Manning WJ, Solomon SD: Vitamin D therapy and cardiac structure and function in patients with chronic kidney disease: the PRIMO randomized controlled trial. JAMA 2012;307:674-684.

33 EVOLVE Trial Investigators, Chertow GM, Block GA, Correa-Rotter R, Drüeke TB, Floege J, Goodman WG, Herzog CA, Kubo Y, London GM, Mahaffey KW, Mix TC, Moe SM, Trotman ML, Wheeler DC, Parfrey PS: Effect of cinacalcet on cardiovascular disease in patients undergoing dialysis. N Engl J Med 2012;367:2482-2494.

34 Kiykim AA, Horoz M, Ozcan T, Yildiz I, Sari $S$, Genctoy G: Pulmonary hypertension in hemodialysis patients without arteriovenous fistula: the effect of dialyzer composition. Ren Fail 2010;32:1148-1152.

35 Humbert M, Sitbon O, Simonneau G: Treatment of pulmonary arterial hypertension. $\mathrm{N}$ Engl J Med 2004;351:1425-1436.

-36 Lawrie A, Waterman E, Southwood M, Evans D, Suntharalingam J, Francis S, Crossman D, Croucher P, Morrell N, Newman C: Evidence of a role for osteoprotegerin in the pathogenesis of pulmonary arterial hypertension. Am J Pathol 2008;172:256-264.

37 Wang Z, Chesler NC: Pulmonary vascular wall stiffness: an important contributor to the increased right ventricular afterload with pulmonary hypertension. Pulm Circ 2011;1:212223.

38 Chen S, Law CS, Grigsby CL, Olsen K, Gardner DG: A role for the cell cycle phosphatase Cdc25a in vitamin D-dependent inhibition of adult rat vascular smooth muscle cell proliferation. J Steroid Biochem Mol Biol 2010;122: 326-332.

39 Schoppet M, Shroff RC, Hofbauer LC, Shanahan CM: Exploring the biology of vascular calcification in chronic kidney disease: what's circulating? Kidney Int 2008;73:384-390.

40 Moe SM, Reslerova M, Ketteler M, O’Neill K, Duan D, Koczman J, Westenfeld R, JahnenDechent W, Chen NX: Role of calcification inhibitors in the pathogenesis of vascular cal- cification in chronic kidney disease. Kidney Int 2005;67:2295-2304.

41 Passauer J, Pistrosch F, Bussemaker E, Lassig G, Herbrig K, Gross P: Reduced agonist-induced endothelium-dependent vasodilation in uremia is attributable to an impairment of vascular nitric oxide. J Am Soc Nephrol 2005; 16:959-965.

42 Tonelli AR, Aytekin M, Feldstein AE, Dweik RA: Leptin levels predict survival in pulmonary arterial hypertension. Pulm Circ 2012;2: 214-219.

43 Scholze A, Rattensperger D, Zidek W, Tepel M: Low serum leptin predicts mortality in patients with chronic kidney disease stage 5 . Obesity (Silver Spring) 2007;15:1617-1622.

44 McIntyre CW, Burton JO, Selby NM, Leccisotti L, Korsheed S, Baker CS, Camici PG: Hemodialysis-induced cardiac dysfunction is associated with an acute reduction in global and segmental myocardial blood flow. Clin J Am Soc Nephrol 2008;3:19-26.

45 Nicholl DD, Ahmed SB, Loewen AH, Hemmelgarn BR, Sola DY, Beecroft JM, Turin TC, Hanly PJ: Declining kidney function increases the prevalence of sleep apnea and nocturnal hypoxia. Chest 2012;141:1422-1430.

-46 Janda S, Shahidi N, Gin K, Swiston J: Diagnostic accuracy of echocardiography for pulmonary hypertension: a systematic review and meta-analysis. Heart 2011;97:612-622.

$\checkmark 47$ Fisher MR, Forfia PR, Chamera E, HoustenHarris T, Champion HC, Girgis RE, Corretti MC, Hassoun PM: Accuracy of Doppler echocardiography in the hemodynamic assessment of pulmonary hypertension. Am J Respir Crit Care Med 2009;179:615-621.

48 Haddad F, Hunt SA, Rosenthal DN, Murphy DJ: Right ventricular function in cardiovascular disease. I: Anatomy, physiology, aging, and functional assessment of the right ventricle. Circulation 2008;117:1436-1448.

49 Burton JO, Jefferies HJ, Selby NM, McIntyre CW: Hemodialysis-induced cardiac injury: determinants and associated outcomes. Clin J Am Soc Nephrol 2009;4:914-920.

50 Barst RJ, Rubin LJ, Long WA, McGoon MD, Rich S, Badesch DB, Groves BM, Tapson VF, Bourge RC, Brundage BH, Koerner SK, Langleben D, Keller CA, Murali S, Uretsky BF, Clayton LM, Jobsis MM, Blackburn SD, Shortino D, Crow JW: A comparison of continuous intravenous epoprostenol (prostacyclin) with conventional therapy for primary pulmonary hypertension. N Engl J Med 1996; 334:296-301.

51 Channick RN, Simonneau G, Sitbon O, Robbins IM, Frost A, Tapson VF, Badesch DB, Roux S, Rainisio M, Bodin F, Rubin LJ: Effects of the dual endothelin-receptor antagonist bosentan in patients with pulmonary hypertension: a randomised placebo-controlled study. Lancet 2001;358:1119-1123.

52 Galie N, Ghofrani HA, Torbicki A, Barst RJ, Rubin LJ, Badesch D, Fleming T, Parpia T, Burgess G, Branzi A, Grimminger F, Kurzyna M, Simonneau G: Sildenafil citrate therapy for pulmonary arterial hypertension. N Engl J Med 2005;353:2148-2157. 